\title{
REVIEW
}

\section{Evidence-based management of upper tract urolithiasis in the spinal cord-injured patient}

\author{
S Ramsey and C McIlhenny \\ Department of Urology, Stirling Royal Infirmary, Stirling, UK
}

\begin{abstract}
Objective: The objective is to review the published literature on the aetiology and evidence-based management of stone disease in the spinal cord-injured patient.

Methods: A PubMed and Medline search was performed using the terms 'spinal cord injury', 'paraplegia', 'stone', 'nephrolithiasis', 'urolithiasis', 'calculus', 'spinal cord injury' or 'paraplegia' with 'SWL', 'ureteroscopy', 'chemolysis' and 'PCNL.' The Cochrane database, the National Institute for Clinical Excellence guidelines and the Scottish Intercollegiate guidelines were searched using the terms 'spinal cord injury' and 'urolithiasis' and 'nephrolithiasis'.

Results: A total of 32 papers were identified, mainly case series or case-cohort studies with few contemporary papers. The risk of developing a renal stone after spinal cord injury (SCI) is between 7 and $20 \%$ over a period of 8-10 years. Stone formation may be related to early demineralisation of bone or chronic infection. Biochemical abnormalities are not significantly different between stone-forming and non-stone forming patients, though these patients differ from healthy controls. Presentation may be atypical, but is most commonly recurrent urinary tract infection. Treatment may be complicated by lower limb contractures limiting retrograde access. Several case series report success with shock wave lithotripsy varying from 50 to $70 \%$, though comparisons are limited by heterogeneous indications and reporting. Percutaneous nephrolithotomy remains the gold standard for stones measuring $2 \mathrm{~cm}$ and above. Stone-free rates of $90 \%$ have been reported, though surgery was often complex with higher complication rates.

Conclusion: Management of upper urinary tract stones in patients with $\mathrm{SCl}$ is complex regarding surgical technique, post-operative care and recurrence rates. Further contemporary case series must use standardised reporting tools to allow valid comparisons.
\end{abstract}

Spinal Cord (2011) 49, 948-954; doi:10.1038/sc.2011.50; published online 31 May 2011

Keywords: nephrolithiasis; shock-wave lithotripsy; percutaneous nephrolithotomy; paraplegia; quadriplegia; treatment

\section{Introduction}

Patients with spinal cord injury (SCI) are more prone to a number of urological complications including the formation of upper urinary tract stones. This is a common complication, which has remained relatively static in incidence over the last 25 years. ${ }^{1}$ Physiological factors such as upper urinary tract stasis, reflux, chronic infection and method of bladder management may be responsible for this increased risk, as well as underlying metabolic changes.

Recently, the 'Guy's Stone Score' ${ }^{2}$ has been proposed to classify the complexity of stones treated by percutaneous nephrolithotomy (PCNL) to allow inter-unit comparison of outcomes rates and complications. The authors suggest patients with a SCI should be classified as IV, the most

Correspondence: Dr S Ramsey, Department of Urology, Stirling Royal Infirmary, Stirling FK8 2AU, UK.

E-mail: sara.ramsey@nhs.net

Received 31 January 2011; revised 22 March 2011; accepted 8 April 2011; published online 31 May 2011 complex. Certainly there are particular physiological and anatomical implications for stone management in patients with SCI. These patients are more likely to develop chronic or recurrent stone disease, and treatment of their stones may be more complex because of coexisting medical and physical conditions. However, out with specialist spinal centres, these patients are often managed by general urologists and those with an interest in reconstructive and functional urology rather than endourologists. This review examines current literature on the aetiology and the evidence base for management of nephrolithiasis in patients with SCI.

\section{Methods}

A PubMed and Medline search of all English language articles from 1960 was carried out using the terms 'spinal cord injury', 'paraplegia', 'stone', 'nephrolithiasis', 'urolithiasis', 'calculus', and 'spinal cord injury' or 'paraplegia' with 'ESWL', 
'ureteroscopy', 'chemolysis' and 'PCNL'. The Cochrane database, the National Institute for Clinical Excellence guidelines and the Scottish Intercollegiate guidelines were searched using the terms 'spinal cord injury','urolithiasis' and 'nephrolithiasis', and no relevant guidelines or metaanalyses were identified (Grade A recommendation.) Levels of evidence were assessed using the Oxford Centre for Evidence-based Medicine Levels of Evidence Model. No systematic reviews (Level 1a) or prospective cohort studies were identified (Level 1b). Articles dealing with bladder stones alone were excluded, as the focus of the review is upper urinary tract stones. Single-patient case reports were excluded, unless they reported on treatment of urolithiasis in spinal cord-injured patients. Articles were reviewed by a single author, and the results classified into subsections regarding aetiology, metabolic issues, presentation and treatment of stone disease.

\section{Results}

A total of 32 studies were identified dating from 1978 to 2006. The majority were case series (Level 4) with some case control and limited cohort studies (Level 3b).

\section{Aetiology and epidemiology}

The risk of developing a renal stone after SCI is quoted as $7-20 \%$ over a period of $8-10$ years. $^{3-5}$ As with the general population, males have a somewhat higher risk of stone formation than females. ${ }^{3}$ The two longitudinal studies of patients with SCI, based on a national database have suggested the incidence has remained static over the last 25 years, despite advances in bladder drainage, antibiotic use and upper tract imaging. ${ }^{1,3}$ The reasons for this remain unclear.

The risks of stone formation are highest in the first few months following the injury, cited as the initial 3 months in the Alabama study, ${ }^{3}$ and 6 months in the Danish study. ${ }^{5}$ This initial phase of stone formation is most likely due to early demineralisation of the bones of the lower limbs, leading to so called 'immobilisation hypercalciuria'. ${ }^{6}$ The second phase of stone formation is more chronic and usually related to infection with urease-producing bacteria.

The geographic variation of stone disease found by the general population is mirrored in patients with SCI. In a study based on the United States SCI database, stone incidence increased with increasing temperature and decreasing latitude, suggesting geographic factors may also have a role in stone formation. ${ }^{3}$

Recurrence rates for stone disease are also important in the SCI population. One case control study reports $72 \%$ of stone formers had a further upper tract stone within 2 years. ${ }^{7}$ Another longitudinal study reports significant, but somewhat lower, rates of recurrence, of $34 \%$ over 5 years, which is somewhat closer to the risks for the general population. ${ }^{8}$ It is likely these recurrence rates are related to the underlying stone aetiology such as chronic infection that is not easily corrected.
There is a complex interplay between the formation of bladder stones, method of bladder drainage, and formation of upper tract stones. In a case-cohort study, ${ }^{7}$ upper tract stone formers were significantly more likely to have had a previous bladder stone than non-stone formers (48 vs $15 \%, P<0.001$.) In this study, patients were also more likely to form stones, if they had vesico-ureteric reflux or had a neurologically complete cervical lesion. Two other studies suggest the presence of an indwelling Foley catheter may be associated with an increase in renal stone formation, ${ }^{9,10}$ though a more recent study found no association. ${ }^{11}$ Choice of bladder drainage is strongly associated with level of injury that may be a confounding variable. The impact of more widespread use of clean intermittent selfcatheterisation has yet to be assessed regarding stone formation, though theoretically it may lead to reduced stone formation.

Stone composition and metabolic abnormalities

Elevated urinary calcium during the demineralisation phase following injury is common, though other metabolic abnormalities have been implicated following SCI. In one comparative study between stone formers and non-stone formers with SCI, $16 \%$ of patients had hypercalciuria on 24-h collection and 30\% had hyperuricaemia, though there were no significant differences between the two groups of patients. $^{12}$ A similar case-cohort study of stone formers and non-stone formers cited no difference in serum calcium or urinary $\mathrm{pH}$ between the two groups, though on longer follow-up 5 of the 100 non-stone formers subsequently went on to form stones. ${ }^{7}$ In a follow-up study by this group, urinary citrate levels were lower in patients with SCI than healthy controls, but again this level was not significantly different between the stone-forming and non-stone forming patients with SCI. Similar results were noted for inorganic pyrophosphate and other stone inhibitors in this study. ${ }^{13}$ As these three studies suggest metabolic abnormalities are common in patients with SCI, regardless of stone formation, other stone inhibitors or less measurable parameters such as urinary stasis must have a role in stone formation.

Few studies have assessed the biochemical composition of upper urinary tract stones cleared from patients with SCI. One of the study that included bladder and upper tract stones from 148 patients concluded that $98 \%$ of stones were of calcium phosphate (apatite) and magnesium ammonium phosphate (struvite). ${ }^{14}$ However, all the kidney stones removed were from patients who had been injured for at least 2 years, which may have confounded the results by predisposing to chronic infection-related stones.

\section{Presentation of stone disease in SCI patients}

It is recognised that patients with SCI, particularly above T6 may well not present with any classical symptoms of colic. Autonomic dysreflexia may result from hydronephrosis in patients with lesions above T6. In one analysis of 1669 SCI patients over 15 years, ${ }^{10} 3.5 \%$ developed upper tract stones. The most common presentation leading to a stone diagnosis was recurrent infection, with over a fifth of the 
reported stone episodes presenting acutely with urosepsis. Only $11 \%$ were asymptomatic and in this study two-thirds of the stones were measuring over $1 \mathrm{~cm}$ in size, suggesting rapid stone formation. One case series of four patients with silent pyonephrosis cautions that stone presentation may be very nonspecific in patients with SCI and includes increased spasms, sweating and nonspecific abdominal discomfort. ${ }^{15}$

Suggested guidelines in the United Kingdom for the urological management of patients with SCI recommend upper tract surveillance with an annual ultrasound (Level $5)^{16}$ There is currently no published evidence regarding the incidence of asymptomatic stones detected on annual follow-up, or regarding the role of CT surveillance of the upper tracts in this group of patients.

Treatment of stones in patients with SCI

Pre-operative planning. Patients with indwelling catheters usually have urine colonised with bacteria. Sensitivities preoperative should be noted and antibiotic prophylaxis should be altered appropriately. Staff in pre-assessment clinics should be aware that the urine cannot be 'sterilised' to prevent multiple courses of unnecessary antibiotics for colonisation rather than symptomatic infection. Assessment of contractures and range of movement, particularly in the lower limbs are highly important as patients may not be able to be placed into the required lithotomy position for what would otherwise be a straightforward ureteroscopy. ${ }^{17}$ The difficulty in gaining satisfactory retrograde ureteric access due to body habitus, contractures, and the presence of lower tract diversion are probably the largest contributory factor rendering stones in patients with SCI complex. ${ }^{17}$

Shock wave lithotripsy. The most common stone in patients with SCI is struvite, which is soft and radio-opaque. Although this should favour SWL in stone treatment, the atypical presentation in patients with SCI means these stones are often large when diagnosed. At least six case series describing SWL in a cohort of patients with SCI have been published (Level 4). ${ }^{18-23}$ There are no more contemporary series than those in the late 1990s and all have relatively small numbers of patients (see Tables 1-3). No case control or comparative trial was identified. Success rates vary and stone-free rates vary from $50 \%$ to over $70 \%$ but interpretation of the studies is limited because of the range of stone sizes, locations and techniques used. These papers are very heterogenous in their reporting of stone burden, ancillary procedures and outcomes (Tables 2 and 3). Clearly in these series, SWL has been applied for much larger and more complex stones than would usually be considered in fully fit patients. Single-patient case studies have reported on the feasibility of SWL in patients with baclofen pumps and cardiac pacemakers. ${ }^{24,25}$ SWL is feasible without additional anaesthesia in most patients, and the rates of intra-operative complications such as autonomic hyperreflexia are low with only one episode of dysreflexia reported in the 101 patients

Table 1 SWL technical considerations

\begin{tabular}{|c|c|c|c|c|c|}
\hline $\begin{array}{l}\text { Author (year), } \\
\text { (level of evidence) }\end{array}$ & No. of patients & $\begin{array}{c}\text { Anaesthesia GA/ } \\
\text { spinal/sedated or } \\
\text { local/none }\end{array}$ & $\begin{array}{l}\text { No. of sessions } \\
1 / 2 / \geqslant 3\end{array}$ & $\begin{array}{l}\text { Lithotriptor } \\
\text { type+no. of shocks }\end{array}$ & $\begin{array}{l}\text { Hospital stay days } \\
\text { average (range) }\end{array}$ \\
\hline Lazare (1988), (Level 4) & 32 (41 renal units, 46 sessions) & $28 / 15 / 3 / 0$ & $31 / 2 / 1$ & $\begin{array}{l}\text { Dornier HM-3 1580, } \\
\max 2400 .\end{array}$ & Not given \\
\hline Spirnak (1988), (Level 4) & 5 (8 renal units, 10 sessions) & $0 / 0 / 2 / 3$ & $4 / 1 / 0$ & Dornier HM-3 & $17(5-43)$ \\
\hline Niedrach (1991), (Level 4) & 11 (13 renal units, 19 sessions) & $8 / 6 / 1 / 0$ & Not given & $\begin{array}{l}\text { Dornier HM-3 } \\
2350 \text { ( } 2376 \text { unilateral, } \\
2250 \text { bilateral) }\end{array}$ & $3.3(1-8)$ \\
\hline Sugiyama (1992), (Level 4) & $\begin{array}{l}23 \text { ( } 26 \text { renal units, } 31 \text { sessions), } \\
\text { (19 SCl, } 4 \text { other, } 2 \text { not treated) }\end{array}$ & $15 / 4 / 0 / 12$ & $17 / 3 / 1$ & $\begin{array}{l}\text { Dornier HM-3 } \\
\text { max } 2400 \text { per kidney }\end{array}$ & 2 (Not given) \\
\hline Deliveliotis (1993), (Level 4) & 15 (6 SCl, 9 other) & $0 / 0 / 0 / 15$ & $7 / 8 / 0$ & $\begin{array}{l}\text { Dornier HM-3 } \\
\text { HM-4 } \\
1500-3000\end{array}$ & Not given \\
\hline Robert (1995), (Level 4) & 15 & $0 / 0 / 3 / 12$ & $1-7$ (mean 4.2) & EDAP LT 01 Not given & Not given \\
\hline
\end{tabular}

Abbreviations: GA, general anaesthesia; $\mathrm{SCl}$, spinal cord injury; SWL, shock wave lithotripsy.

Table 2 SWL stone factors

\begin{tabular}{|c|c|c|c|c|c|}
\hline $\begin{array}{l}\text { Author (year), } \\
\text { (Level of evidence) }\end{array}$ & $\begin{array}{l}\text { Av stone burden }(\mathrm{cm}), \\
\text { (size range, } \mathrm{cm})\end{array}$ & No. of stones & $\begin{array}{l}\text { Bilateral } \\
\text { stones }\end{array}$ & $\begin{array}{c}\text { Stone site (largest stone pelvis/upper/mid/lower } \\
\text { calyx/upper ureter }\end{array}$ & $\begin{array}{l}\text { Staghorn } \\
\text { Partial/Full }\end{array}$ \\
\hline Lazare (1988), (Level 4) & 2.9 & 1.5 per unit & 9 & Not given & $2 / 5$ \\
\hline Spirnak (1988), (Level 4) & Not given & Not given & 3 & Not given & $1 / 1$ \\
\hline Niedrach (1991), (Level 4) & $3.34(0.8-6.2)$ & $1-5$ & 2 & $5 / 2 / 2 / 4 / 0$ & Not given \\
\hline Sugiyama (1992), (Level 4) & $2.29(0.5-7.0)$ & Not given & 8 & Not given & $0 / 6$ \\
\hline Deliveliotis (1993), (Level 4) & Not given (0.5-3.0) & Not given & 1 & Not given & $0 / 2$ \\
\hline Robert (1995), (Level 4) & $0.11(0.5-3.5)$ & Not given & 1 & $3 / 18$ calyces, no location/2 & Not given \\
\hline
\end{tabular}


Table 3 SWL outcomes

\begin{tabular}{|c|c|c|c|c|c|c|}
\hline $\begin{array}{l}\text { Author (Year) } \\
\text { Level of evidence }\end{array}$ & $\begin{array}{l}\text { Adjuvant procedures } \\
\text { (Pre SWL) }\end{array}$ & $\begin{array}{l}\text { Ancillary procedures } \\
\text { (Post SWL) }\end{array}$ & $\begin{array}{l}\text { Autonomic dysreflexia/ } \\
\text { intra-op complications }\end{array}$ & $\begin{array}{l}\text { Post-op } \\
\text { complications }\end{array}$ & $\begin{array}{l}\text { Success (stone } \\
\text { free rate, \%) }\end{array}$ & $\begin{array}{l}\text { Residual } \\
\text { stone size }\end{array}$ \\
\hline Lazare (1988), (Level 4) & 24 nephrostomy/stent & $\begin{array}{l}2 \text { nephrostomy } \\
1 \text { PCNL } \\
1 \text { basketing }\end{array}$ & $0 / 0$ & 1 sepsis & 73 & Not given \\
\hline Spirnak (1988), (Level 4) & 6 nephrostomy/stent & 1 nephrostomy & $0 / 2$ hypertension & Not given & 60 & Not given \\
\hline Niedrach (1991), (Level 4) & $\begin{array}{l}4 \text { nephrostomy } \\
3 \text { percutaneous stone } \\
\text { manipulation }\end{array}$ & $\begin{array}{l}6 \text { nephrostomy } \\
4 \text { ureteric catheter/stent }\end{array}$ & $\begin{array}{l}0 / 1 \text { hypertension } \\
1 \text { hypotension } \\
1 \text { bradycardia }\end{array}$ & 2 sepsis & No stone free & Not given \\
\hline Sugiyama (1992), (Level 4) & Not given & $\begin{array}{l}2 \text { cystolithopaxy } \\
3 \text { PCNL } \\
2 \text { urethroscopy } \\
1 \text { basketing }\end{array}$ & $\begin{array}{l}1 \text { dysreflexia/ } 1 \text { severe } \\
\text { spastic contractures } \\
\text { requiring } G A\end{array}$ & $\begin{array}{l}1 \text { calyceal } \\
\text { perforation }\end{array}$ & 53 & 0.41 \\
\hline Deliveliotis (1993), (Level 4) & 5 stents & 0 & $\begin{array}{l}0 / 1 \text { hypertension } \\
2 \text { bradycardia }\end{array}$ & 5 UTI/sepsis & 66 & Not given \\
\hline Robert (1995), (Level 4) & $\begin{array}{l}2 \text { stent } \\
1 \text { ureteral } \\
\text { endoprosthesis }\end{array}$ & 2 ureteroscopy+basket & $0 / 0$ & 0 & 53 & Not given \\
\hline
\end{tabular}

Abbreviations: GA, general anaesthesia; intra-op. complications, intra-operative complications; PCNL, percutaneous nephrolithotomy; post-op. complications, post-operative complications; SWL, shock wave lithotripsy; UTI, urinary tract infection.

from six studies. The commonest intra-operative complications were hypertension and bradycardia (Table 3). Few details are given of post-operative complications, though SWL was usually carried out as an inpatient procedure and total hospital stay ranges widely. (Table 1) The proportion of ancillary procedures, both pre and posttreatment, is high, reflecting the larger and more complex stone burden treated (Table 3). As such, SWL should be considered as part of a multimodality strategy in stone treatment, rather than a standalone treatment in patients with SCI. The concept of clinically insignificant residual fragments post-SWL may not be applicable to patients with SCI. Theoretically small residual fragments may act as a nidus for rapid stone recurrence because of residual urease-producing bacteria, though no studies on the natural history of residual fragments in this cohort of patients have been published.

Ureteroscopic. No contemporary series report on the outcomes of ureteroscopic management of upper tract stones in patients with SCI. This is likely to be due to the difficulties in gaining ureteroscopic access as mentioned above. It is recommended that antegrade flexible ureteroscopy after percutaneous access may be the most useful strategy in patients with mid ureteric stones. ${ }^{17}$ The majority of the published series deal with the management of upper urinary tract stones and no published series report outcomes from mid or distal ureteric stones in this cohort of patients. Although ureteroscopic access and treatment may be feasible in some patients, the complete absence of published literature means no evidence-based assessment of this approach can be made.

Percutaneous nephrolithotomy. PCNL is the gold standard for stones measuring $2 \mathrm{~cm}$ and above in the renal pelvis and this remains the case in patients with SCI. Five published series ${ }^{26-30}$ report stone-free rates of around $90 \%$, which at first look appears comparable to the standard PCNL outcomes. (Table 4) However, in the Chicago series all patients had a second-look PCNL as standard, and only 19 renal units were stone free after first PCNL in the UK series. ${ }^{28,30}$ In the earliest study from 1986, there was an average of 2.04 procedures per patient. ${ }^{26}$ In this respect, PCNL in patients with SCI is a more complex and significantly undertaking, often requiring multiple procedures to achieve stone clearance. In the major part of the more contemporary series, 13 out of the 54 procedures required multiple punctures and 23 punctures were supracostal. ${ }^{29}$

Complication rates are fairly high, with three deaths reported in the five studies, and major complications ranging between 6 and 20\%. No standard classification of complications such as the Clavien system has been used in these five series. Major complications include pneumothorax, urosepsis, perirenal abscess and respiratory arrest (Table 4). The United Kingdom series reports that nine patients required intensive care admission, though no details were given regarding the reasons for admission. ${ }^{30}$ Minor complications were also high, but again analysis is limited because of lack of standard classifications. Pyrexia, transfusion and nephrostomy tube dislodgement were the commonest reported complication, and in the major part of the more contemporary series occurred in $75 \%$ of procedures. ${ }^{29}$ Only the UK paper gave details of hospital stay, which was a median of 13 days. $^{30}$ In a study examining all factors predisposing to systemic inflammatory response syndrome and pyrexia post-PCNL in the Netherlands, previous PCNL and spinal injury were significant factors predisposing to systemic inflammatory response syndrome post-op. ${ }^{31}$

Chemolysis. Chemolysis, or the use of agents to encourage stone dissipation as an adjunct to treatment such as ESWL has been reported in small numbers, though there are no specific reports related to patients with SCI. Instillation of Suby G or hemiacidrin through a nephrostomy 
Table 4 PCNL outcomes

\begin{tabular}{|c|c|c|c|c|}
\hline Author (year), (Level of evidence) & No. of patients & Stone free (\%) & Major complications & Minor complications \\
\hline Culkin (1986), (Level 4) & $\begin{array}{l}23 \text { patients ( } 28 \text { renal units, } \\
47 \text { procedures) }\end{array}$ & 90 & $\begin{array}{l}\quad 8.5 \% \\
1 \text { respiratory arrest } \\
2 \text { perirenal abscess } \\
1 \text { hydrothorax }\end{array}$ & $\begin{array}{l}64 \% \text { pyrexia } \\
14 \% \text { retained stones } \\
13 \% \text { dislodges tubes } \\
17 \% \text { transfusion }\end{array}$ \\
\hline Culkin (1990), (Level 3b) & 35 patients & 86 & $\begin{array}{l}\quad 20 \% \\
1 \text { death } \\
1 \text { respiratory arrest } \\
3 \text { perirenal abscess } \\
1 \text { hydrothorax } \\
1 \text { aspiraton pneumonia } \\
1 \text { nephrocolonic fistula }\end{array}$ & Not given \\
\hline Rubenstein (2004), (Level 4) & $\begin{array}{l}23 \text { patients ( } 100 \text { procedures } \\
\text { on } 47 \text { renal units) }\end{array}$ & 96 & $\begin{array}{l}\quad 18 \% \\
1 \text { sepsis with ITU } \\
1 \text { hydrothorax } \\
1 \text { retroperitoneal abscess } \\
1 \text { nephrocutaneous fistula }\end{array}$ & $\begin{array}{l}17 \text { fever } \\
1 \text { transfusion }\end{array}$ \\
\hline Lawrentschuk (2005), (Level 4) & $\begin{array}{l}26 \text { patients ( } 54 \text { procedures } \\
\text { on } 32 \text { renal units) } \\
13 \text { multiple punctures, } \\
23 \text { supracostal }\end{array}$ & $\begin{array}{l}87 \text { (92 for PCNL+ } \\
\text { adjuvant measures) }\end{array}$ & $\begin{array}{l}\quad 6 \% \\
2 \text { pneumothorax } \\
1 \text { urosepsis }\end{array}$ & $\begin{array}{l}77 \% \text { overall } \\
15 \text { pyrexia }(58 \%) \\
3 \text { transfusion }(12 \%) \\
2 \text { calyceal perforation }(8 \%)\end{array}$ \\
\hline Symons (2006), (Level 4) & $\begin{array}{l}29 \text { patients ( } 39 \text { procedures } \\
\text { on } 32 \text { renal units) }\end{array}$ & 62 & $\begin{array}{l}\quad 8 \% \\
2 \text { deaths } \\
1 \text { seizures, } 1 \text { aspiration } \\
\text { pneumonia } \\
1 \text { pressure necrosis } \\
9 \text { ITU admissions }\end{array}$ & $\begin{array}{l}9 / 32 \\
18 \% \text { pyrexia, others } \\
\text { hypotension, nephrostomy } \\
\text { tube leakage }\end{array}$ \\
\hline
\end{tabular}

Abbreviation: ITU, intensive therapy unit; PCNL, percutaneous nephrolithotomy.

tube can cause crystal dissolution and has been used as an adjunct to SWL or occasionally as single treatment in particularly for unfit patients. The process is slow, and care should be taken to maintain intrarenal pressure below $25 \mathrm{~cm}$ water to prevent pyelolymphatic backflow and precipitating bacteriaemia. $^{32}$

\section{Discussion}

SCI patients have an increased risk of nephrolithiasis due to multiple aetiological factors such as stasis, reflux and chronic infection, and require lifelong surveillance of their upper tracts. However, it remains unclear from metabolic studies why some SCI patients develop stones and others do not. The atypical nature of presentation and the relatively high rates of acute sepsis from urolithiasis require a high index of suspicion from clinicians dealing with SCI patients. The impact of method of bladder management on upper tract stone formation is unclear from the literature. Early management of the lower urinary tract with adequate bladder drainage, and use of intermittent self-catheterisation when feasible has been recommended by the UK expert body of urologists. This practice should aid in reduction of upper tract stones through improved drainage and reduction in chronic infection but no there is no consensus in the evidence to confirm this theory. Similarly, understanding of the deleterious effect of reflux, high bladder pressures and regular upper tract surveillance all should theoretically lead to a reduction in the incidence of upper tract stone formation, though no reports of reduced incidence have yet been published. It may be that improved surveillance has led to an increased detection rate, which coupled with a reduced stone formation rate has lead to an apparently static stone incidence. The authors await further papers from the large American SCI patient databases to reflect trends in twenty-first century stone incidence.

Current literature on stone management specifically in the spinal cord-injured patient is limited. The majority of publications reporting on SWL in these patients dates from over 20 years ago. The published literature on SWL is predominantly single-centre case series, and heterogeneous in stone size and location, as well as outcome measures such as ancillary and auxillary procedures. It is not known if the lack of contemporary reports with SWL reflects a shift in treatment to other modalities. The previously described relatively rapid formation of stones by Donellan et al. ${ }^{10}$ may lead to stones being considered too large for a trial of SWL, or the high rates of additional stone procedures may have led to SWL falling out of favour. Certainly the published series would suggest SWL is a relatively safe and well-tolerated procedure, which can achieve reasonable stone clearance, though probably it should be considered as part of a multimodality treatment approach. It would be interesting to see the outcomes with a modern lithotripter, and patients with a relatively homogenous stone burden.

In contrast to the SWL literature, there are significantly more contemporary studies reporting on PCNL in the spinal cord-injured patient. These papers support PCNL as the gold standard for the management of large upper tract stones, though significant complications are reported including death and sepsis requiring intensive care support. Only one 
study of PCNL includes patients with and without SCI. Although this was not a case control study reporting on overall complications, the finding that the presence of SCI was a significant predictor of developing features of the systemic inflammatory response syndrome is important for peri-operative management. Given the higher risk of sepsis as well as other considerations such as dysreflexia, increased levels of post-operative care such as high-dependency need to be considered routinely. To date, no studies have reported on use of supine PCNL, which may aid in the often challenging positioning of a patient with SCI in the prone position. Stone-free rates are relatively high in all, but one, study; however, comparison between studies is limited by heterogeneity including routine second-look procedures and use of multiple punctures. Again as with SWL, standardised reporting of stone-free rates, ancillary procedures, and standardised classification of post-operative complications must be considered for further case series in the twenty-first century.

Dissolution therapy for upper tract stones is certainly technically feasible, and still appears in textbooks and examination papers. However, there are no recent reports on its use and no reports relating to SCI patients specifically. It appears to have largely been confined to the history books because of improved endoscopic techniques and equipment.

In conclusion, management of upper urinary tract stones in patients with SCI is complex, regarding surgical technique and post-operative care. Recurrence rates are high, and these patients may require specialist stone management from endourologists in addition to ongoing management from general or reconstructive urologists. The UK guidelines for urological management of patients with SCI comment on the lack of high-quality literature and as such have devised their guidelines based on expert opinion. Stone management in the SCI patient appears just as lacking in higher level evidence, despite widespread adoption of standard reporting of stone-free rates and ancillary procedures by the endourological community. Clearly twenty-first century reports of stone management in cohorts of SCI patients using standardised reporting tools are needed to strengthen our knowledge with these complex patients.

\section{Conflict of interest}

The authors declare no conflict of interest.

\section{References}

1 Chen Y, DeVivo MJ, Stover SL, Lloyd LK. Recurrent kidney stone: a 25 -year follow-up study in persons with spinal cord injury. Urology 2002; 60: 228-232. (Level 3b).

2 Smith N, Hegarty N, Glass J. Novel system for grading complexity of PCNL procedures: the Guy's Stone Score. Abstract 824 EAU Annual Meeting, Stockholm 2009.

3 Chen Y, DeVivo MJ, Roseman JM. Current trend and risk factors for kidney stones in persons with spinal cord injury: a longitudinal study. Spinal Cord 2000; 38: 346-353. (Level 2b).

4 DeVivo MJ, Fine PR, Cutter GR, Maetz HM. The risk of renal calculi in spinal cord injury patients. J Urol 1984; 131: 857-860. (Level 2b).
5 Hansen RB, Biering-Sørensen F, Kristensen JK. Urinary calculi following traumatic spinal cord injury. Scand J Urol Nephrol 2007; 41: 115-119. (Level 3b).

6 Naftchi NE, Viau AT, Sell GH, Lowman EW. Mineral metabolism in spinal cord injury. Arch Phys Med Rehabil 1980; 61: 139-142. (Level 3b).

7 DeVivo MJ, Fine PR. Predicting renal calculus occurrence in spinal cord injury patients. Arch Phys Med Rehabil 1986; 67: 722-725. (Level 3b).

8 Chen Y, Roseman JM, Devivo MJ, Funkhouser E. Does fluid amount and choice influence urinary stone formation in persons with spinal cord injury? Arch Phys Med Rehabil 2002; 83: 1002-1008. (Level 3b).

9 Hall MK, Hackler RH, Zampieri TA, Zampieri JB. Renal calculi in spinal cord-injured patient: association with reflux, bladder stones, and foley catheter drainage. Urology 1989; 34: 126-128. (Level 3b).

10 Donnellan SM, Bolton DM. The impact of contemporary bladder management techniques on struvite calculi associated with spinal cord injury. BJU Int 1999; 84: 280-285. (Level 3b).

11 Sugimura T, Arnold E, English S, Moore J. Chronic suprapubic catheterization in the management of patients with spinal cord injuries: analysis of upper and lower tract complications. BJU Int 2008; 101: 1396-1400. (Level 3b).

12 Burr RG, Nuseibeh I. Biochemical studies in paraplegic renal stone patients. 1. Plasma biochemistry and urinary calcium and saturation. Br J Urol 1985; 57: 269-274. (Level 3b).

13 Burr RG, Nuseibeh I, Abiaka CD. Biochemical studies in paraplegic renal stone patients. 2. Urinary excretion of citrate, inorganic pyrophosphate, silicate and urate. Br J Urol 1985; 57: 275-278. (Level 3b).

14 Burr RG. Urinary calculi composition in patients with spinal cord lesions. Arch Phys Med Rehabil 1978; 59: 84-88. (Level 4).

15 Vaidyanathan S, Singh G, Soni BM, Hughes P, Watt JW, Dundas S et al. Silent hydronephrosis/pyonephrosis due to upper urinary tract calculi in spinal cord injury patients. Spinal Cord 2000; 38: 661-668. (Level 4).

16 Abrams P, Agarwal M, Drake M, El-Masri W, Fulford S, Reid S et al. A proposed guideline for the urological management of patients with spinal cord injury. BJU Int 2008; 101: 989-994. (Grade D).

17 Ost MC, Lee BR. Urolithiasis in patients with spinal cord injuries: risk factors, management, and outcomes. Curr Opin Urol 2006; 16: 93-99. (Level 3a).

18 Lazare JN, Saltzman B, Sotolongo J. Extracorporeal shock wave lithotripsy treatment of spinal cord injury patients. J Urol 1988; 140: 266-269. (Level 4).

19 Spirnak JP, Bodner D, Udayashankar S, Resnick MI. Extracorporeal shock wave lithotripsy in traumatic quadriplegic patients: can it be safely performed without anesthesia? J Urol 1988; 139: 18-19. (Level 4).

20 Niedrach WL, Davis RS, Tonetti FW, Cockett AT. Extracorporeal shock-wave lithotripsy in patients with spinal cord dysfunction. Urology 1991; 38: 152-156. (Level 4).

21 Sugiyama T, Fugelso P, Avon M. Extracorporeal shock wave lithotripsy in neurologically impaired patients. Semin Urol 1992; 10: 109-111. (Level 4).

22 Deliveliotis C, Picramenos D, Kostakopoulos A, Stavropoulos NI, Alexopoulou K, Karagiotis E. Extracorporeal shock wave lithotripsy in paraplegic and quadriplegic patients. Int Urol Nephrol 1994; 26: 151-154. (Level 4).

23 Robert M, Bennani A, Ohanna F, Guiter J, Avérous M, Grasset D. The management of upper urinary tract calculi by piezoelectric extracorporeal shock wave lithotripsy in spinal cord injury patients. Paraplegia 1995; 33: 132-135. (Level 4).

24 Vaidyanathan S, Hirst R, Parsons KF, Singh G, Soni BM, Oo T et al. Bilateral extracorporeal shock wave lithotripsy in a spinal cord injury patient with a cardiac pacemaker. Spinal Cord 2001; 39: 286-289. (Level 4).

25 Vaidyanathan S, Johnson H, Singh G, Hughes P, Soni BM, Parsons $\mathrm{KF}$ et al. Extra corporeal shock wave lithotripsy of calculi located in lower calyx of left kidney in a spinal cord injury patient who has implantation of baclofen pump in the ipsilateral loin. Spinal Cord 2002; 40: 94-95. (Level 4). 
26 Culkin DJ, Wheeler Jr JS, Nemchausky BA, Fruin RC, Canning JR. Percutaneous nephrolithotomy in the spinal cord injury population. J Urol 1986; 136: 1181-1183. (Level 4).

27 Culkin DJ, Wheeler JS, Nemchausky BA, Fruin RC, Canning JR. Percutaneous nephrolithotomy: spinal cord injury vs. ambulatory patients. I Am Paraplegia Soc 1990; 13: 4-6. (Level 3b).

28 Rubenstein JN, Gonzalez CM, Blunt LW, Clemens JQ, Nadler RB. Safety and efficacy of percutaneous nephrolithotomy in patients with neurogenic bladder dysfunction. Urology 2004; 63: 636-640. (Level 4).

29 Lawrentschuk N, Pan D, Grills R, Rogerson J, Angus D, Webb DR et al. Outcome from percutaneous nephrolithotomy in patients with spinal cord injury, using a single-stage dilator for access. BJU Int 2005; 96: 379-384. (Level 4).

30 Symons S, Biyani CS, Bhargava S, Irvine HC, Ellingham J, Cartledge J et al. Challenge of percutaneous nephrolithotomy in patients with spinal neuropathy. Int J Urol 2006; 13: 874-879. (Level 4).

31 Draga RO, Kok ET, Sorel MR, Bosch RJ, Lock TM. Percutaneous nephrolithotomy: factors associated with fever after the first postoperative day and systemic inflammatory response syndrome. J Endourol 2009; 23: 921-927. (Level 3b).

32 Levy DA, Resnick MI. Management of urinary stones in the patient with spinal cord injury. Urol Clin N Am 1993; 20: 435-442. (Level 3a). 